\title{
Does Male Circumcision Affect Sexual Function, Sensitivity, or Satisfaction?-A Systematic Review
}

\author{
Brian J. Morris, DSc, $\mathrm{PhD}^{*}$ and John N. Krieger, $\mathrm{MD}^{\dagger \neq}$ \\ *School of Medical Sciences, University of Sydney, Sydney, New South Wales, Australia; 'Department of Urology, \\ University of Washington School of Medicine, Seattle, WA, USA; ₹Section of Urology, 112 GU, VA Puget Sound Health \\ Care System, Seattle, WA, USA
}

DOI: $10.1111 / j s m .12293$

\section{A B S T R A C T}

Introduction. Circumcision of males is commonly carried out worldwide for reasons of health, medical need, esthetics, tradition, or religion. Whether circumcision impairs or improves male sexual function or pleasure is controversial.

Aims. The study aims to conduct a systematic review of the scientific literature.

Methods. A systematic review of published articles retrieved using keyword searches of the PubMed, EMBASE, and Cochrane databases was performed.

Main Outcome Measures. The main outcome measure is the assessment of findings in publications reporting original data relevant to the search terms and rating of quality of each study based on established criteria.

Results. Searches identified 2,675 publications describing the effects of male circumcision on aspects of male sexual function, sensitivity, sensation, or satisfaction. Of these, 36 met our inclusion criteria of containing original data. Those studies reported a total of 40,473 men, including 19,542 uncircumcised and 20,931 circumcised. Rated by the Scottish Intercollegiate Guidelines Network grading system, 2 were 1++ (high quality randomized controlled trials) and 34 were case-control or cohort studies (11 high quality: $2++; 10$ well-conducted: $2+; 13$ low quality: $2-$ ). The $1++$, $2++$, and $2+$ studies uniformly found that circumcision had no overall adverse effect on penile sensitivity, sexual arousal, sexual sensation, erectile function, premature ejaculation, ejaculatory latency, orgasm difficulties, sexual satisfaction, pleasure, or pain during penetration. Support for these conclusions was provided by a meta-analysis. Impairment in one or more parameters was reported in 10 of the 13 studies rated as 2-. These lower-quality studies contained flaws in study design (11), selection of cases and/or controls (5), statistical analysis (4), and/or data interpretation (6); five had multiple problems.

Conclusion. The highest-quality studies suggest that medical male circumcision has no adverse effect on sexual function, sensitivity, sexual sensation, or satisfaction. Morris BJ and Krieger JN. Does male circumcision affect sexual function, sensitivity, or satisfaction?-A systematic review. J Sex Med **;**:**_**.

Key Words. Circumcision; Erectile Function; Sexual Satisfaction; Premature Ejaculation; Ejaculatory Latency; Penile Sensitivity; Penile Sensation; Male Sexual Function and Pleasure

\section{Introduction}

$M$ ale circumcision is a common procedure that has been performed for thousands of years [1]. The health benefits of male circumcision have been well documented, including substantially lower risks of HIV and other viral and some bacterial sexually transmitted infections; lower rates of penile cancer and possibly prostate cancer; elimination of phimosis, paraphimosis, and balani- tis; and lower rates of urinary tract infections in males during the neonatal period [2,3] and over the lifetime [4]. Female sexual partners of circumcised men have lower rates of cervical cancer, oncogenic types of human papillomavirus, bacterial vaginosis, herpes simplex virus type 2 , Trichomonas vaginalis, and Chlamydia trachomatis $[2,3]$.

In contrast to the established medical benefits of male circumcision, there is continued concern that circumcision may reduce male sexual function 
Table 1 Outcomes from the literature as categorized in this review

\begin{tabular}{|c|c|}
\hline $\begin{array}{l}\text { Type of } \\
\text { outcome }\end{array}$ & Outcome category \\
\hline $\begin{array}{l}\text { Sexual } \\
\text { function }\end{array}$ & $\begin{array}{l}\text { Performance } \\
\text { Erectile dysfunction } \\
\text { Premature ejaculation } \\
\text { Ejaculatory latency time } \\
\text { Orgasm difficulties } \\
\text { Dyspareunia }\end{array}$ \\
\hline Sensitivity & Touch perception of flaccid penis \\
\hline Sensation & $\begin{array}{l}\text { Neurophysiological perception of the penis } \\
\text { or portion of the penis during sexual stimulation }\end{array}$ \\
\hline Satisfaction & $\begin{array}{l}\text { Patient-reported sensation of pleasure } \\
\text { Patient-reported orgasm intensity }\end{array}$ \\
\hline
\end{tabular}

and pleasure. Such concerns could impact decision-making by parents of baby boys and males of all ages, as well as formulation of policies by government bodies and international health organizations. To better inform this discussion, we conducted a systematic review of the literature.

\section{Methods}

\section{Search Strategies}

Articles were retrieved by searching the PubMed, EMBASE, and Cochrane databases on March 25, 2013 using the terms defined in Table 1. Specifically, our strategy included a primary search of the NCBI PubMed database using the keyword circumcision combined with either sexual function, sexual sensitivity, sexual sensation, or sexual satisfaction. Then a secondary search of PubMed used the term circumcision combined with either function, sensation, ejaculation, erection, erectile, sensitivity, satisfaction, dyspareunia or orgasm, to identify additional articles not retrieved by the primary search. Similar strategies were then used to search the EMBASE and Cochrane databases. Titles and abstracts of articles retrieved were reviewed to select those meriting more detailed review. Finally, reference lists of relevant articles were reviewed to identify other relevant studies.

\section{Inclusion Criteria}

Case-control, cohort, and cross-sectional studies were included if the reports contained relevant nonduplicated numerical data arising from physiological testing or population surveys and a rating as described below.

\section{Exclusion Criteria}

We excluded studies that fell into the two lowestquality categories of the grading system (see below). Review articles, case reports, opinion pieces, articles on surgical technique, recovery from surgery, penile histology, conference abstracts, and articles pertaining to female genital cutting (often referred to as "female circumcision") were excluded from our analyses. Scholarly critiques containing no original data or analyses were excluded. We also excluded articles concerning removal of foreskin remnants from circumcised men.

\section{Studies Included}

The database searches identified 2,675 articles305 in the primary search of PubMed, 1,321 in the secondary search of PubMed, and 1,049 in the search of the EMBASE database (Table 2). After

Table 2 Search terms, strategy, and articles retrieved

\begin{tabular}{|c|c|c|c|}
\hline Search term & Total & No. included & References \\
\hline \multicolumn{4}{|l|}{ Primary search of PubMed } \\
\hline Circumcision + sexual function & 200 & 21 & {$[5-26]$} \\
\hline Circumcision + sexual sensitivity & 25 & 8 & {$[5,6,8,12,15,17,25,27]$} \\
\hline Circumcision + sexual sensation & 18 & 3 & {$[8,11,12,28]$} \\
\hline Circumcision + sexual satisfaction & 62 & 19 & {$[5,6,8,10-17,20,22,24-26,29-31]$} \\
\hline \multicolumn{4}{|c|}{ Secondary search of PubMed for articles missed } \\
\hline Circumcision + function & 579 & 3 & {$[32-34]$} \\
\hline Circumcision + sensation & 172 & 2 & {$[33,35]$} \\
\hline Circumcision + ejaculation & 36 & 2 & {$[36,37]$} \\
\hline Circumcision + erection & 90 & 2 & {$[38,39]$} \\
\hline Circumcision + erectile & 90 & 1 & [39] \\
\hline Circumcision + sexual dysfunction & 70 & 1 & [40] \\
\hline Circumcision + sensitivity & 73 & 0 & \\
\hline Circumcision + satisfaction & 147 & 0 & \\
\hline Circumcision + dyspaneunia & 35 & 0 & \\
\hline Circumcision + orgasm & 29 & 0 & \\
\hline \multicolumn{4}{|c|}{ Search of EMBASE for articles missed in searches above } \\
\hline Circumcision + sexual function* & 1,049 & 2 & {$[41,42]$} \\
\hline
\end{tabular}

${ }^{*}$ No additional articles were retrieved by other searches of EMBASE using other search terms, nor of the Cochrane database 
reviewing the titles and abstracts from the primary PubMed search, 51 articles were found that met our inclusion criteria. Elimination of duplicates retrieved using different search terms left 27 unique articles that were suitable for detailed review. The secondary search of PubMed identified 10 more suitable articles not found during the primary search. The subsequent search of EMBASE using circumcision and sexual function yielded two more unique articles that met our inclusion criteria. No additional articles were identified using other search terms. A search of the Cochrane database did not reveal further suitable articles. Finally, searches of reference lists of articles identified one additional study [43]. Thus, the total number of unique publications retrieved by all searches was 39 (Table 2). From these 39, three involving self-selected participants recruited via author-managed anti-circumcision facilities and that investigated psychological phenomena $[28,41,42]$ were removed, leaving 36 for final inclusion. One of the three removed was based entirely on a "preliminary poll" of men unsatisfied with their infant circumcision [42], another presented findings in which data from a cohort of men who have sex with men were combined with data for women [28], and the other, of U.S. men, included data on erectile dysfunction (ED) drug use, which can be recreational [41].

After the detailed searches had been completed, we were alerted to a relevant "in press" metaanalysis [44] that met our inclusion criteria.

\section{Rating of the Evidence}

The studies we included were rated using the Scottish Intercollegiate Guidelines Network (SIGN) grading system for evidence-based guidelines [45] as 1++ (highest quality, namely randomized controlled trials [RCTs] with very low risk of bias, and high-quality meta-analyses) to 4 (lowest quality, namely opinion pieces). Our systematic review excluded articles rated as level 3 (nonanalytical studies) or 4. Thus, the lowest-quality studies in our review were ones rated as SIGN level 2- (casecontrol or cohort studies with a high risk of confounding, bias, or chance and a significant risk that the relationship is not causal).

\section{Synthesis of the Data}

Table 3 summarizes the 36 studies included, categorized by SIGN rating, study design and key findings. To provide consistent terms, Table 3 lists studies under "sensitivity" if the studies reported on the flaccid penis, and under "sensa- tion" if the studies reported on the erect penis. Men assessed before and after circumcision were counted twice, once when uncircumcised and once when circumcised. In total these 36 studies reported data for 40,473 men, including 19,542 uncircumcised and 20,931 who were circumcised, with approximately 9,500 having been circumcised in infancy.

Of the 36 studies, 22 (61\%) had data on premature ejaculation (PE), 19 (53\%) had data on ED, $20(56 \%)$ had data on sexual satisfaction or pleasure, $10(28 \%)$ had data on ejaculatory latency, $8(22 \%)$ had data on pain during intercourse, $6(17 \%)$ had data on orgasm difficulties, $6(17 \%)$ had data on sensitivity, $2(6 \%)$ had data on ease of reaching orgasm, $2(6 \%)$ had data on frequency of having sex, 1 (3\%) had data on sexual arousal, 1 $(3 \%)$ had data on difficulty of insertion, $1(3 \%)$ had data on the penilo-cavernosus reflex, and 1 (3\%) had data on pudendal evoked potentials.

\section{Results}

We first present the findings from the two large RCTs, as these represent level $1++$ evidence. This is followed by subsections on aspects of sexual function, namely ED, PE, orgasm difficulties, difficulty with penetration, and dyspareunia. After that we present findings on penile sensitivity, sexual arousal response, and sexual sensation during arousal, then finally a subsection on sexual satisfaction and pleasure. We present in each subsection findings from physiological studies, if available, followed by survey data. Findings from a meta-analysis of suitable studies of each aspect of sexual function are presented in relevant subsections. Weaknesses in particular studies that justified them being rated as SIGN level 2- are presented in the Discussion.

\section{RCTs}

Two RCTs have been conducted examining various measures of sexual function and satisfaction $[14,15]$. These studies stemmed from RCTs that evaluated circumcision as a potential public health intervention to prevent HIV infections.

The RCT of 2,784 sexually experienced men in Kenya used a behavioral questionnaire to determine five measures (inability to ejaculate, $\mathrm{PE}$, pain during intercourse, sex not pleasurable, difficulty achieving/maintaining an erection) and each participant's medical history for another three measures (erections feel normal, deviation during erection, difficulty achieving erection because skin 


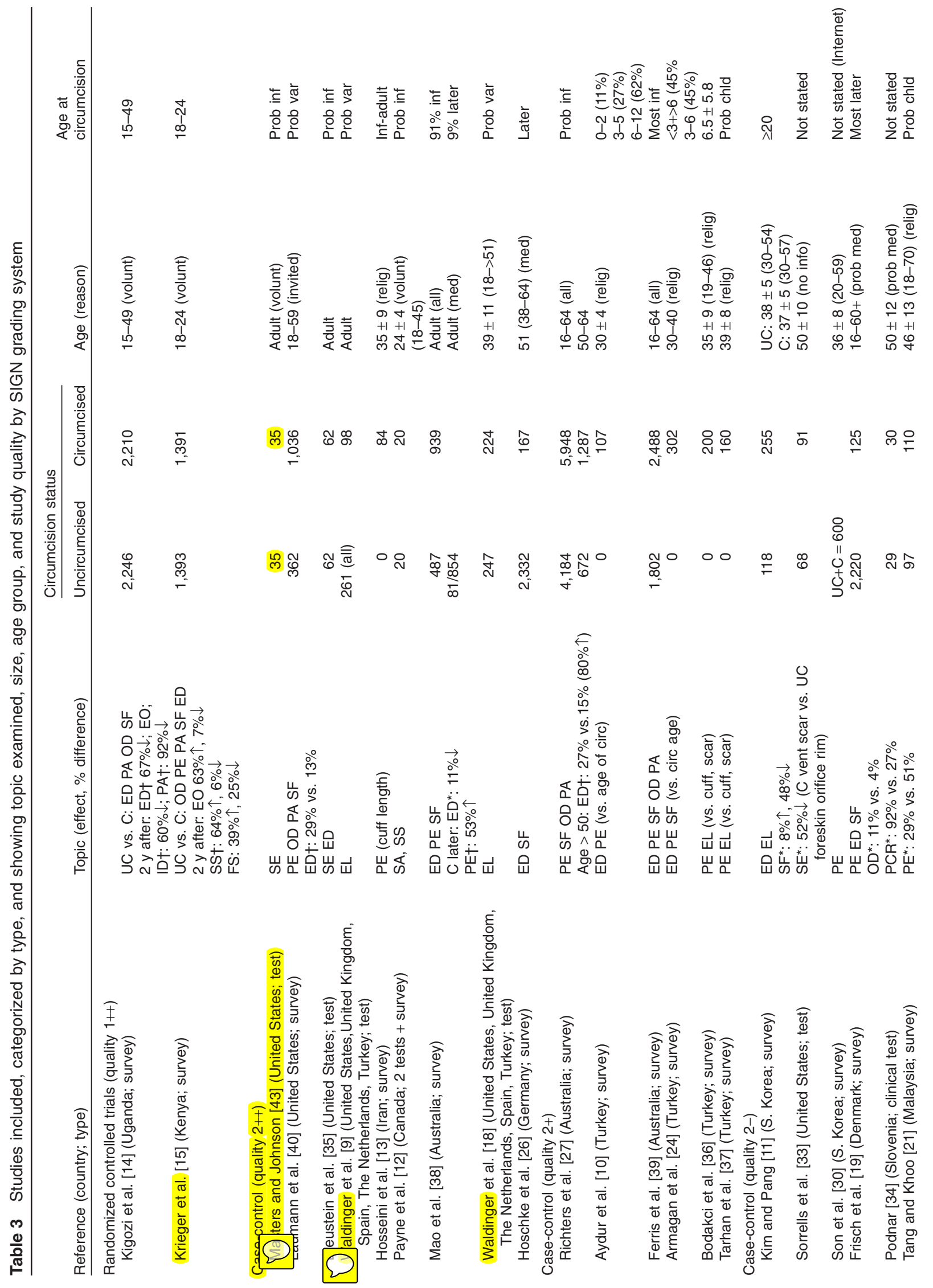




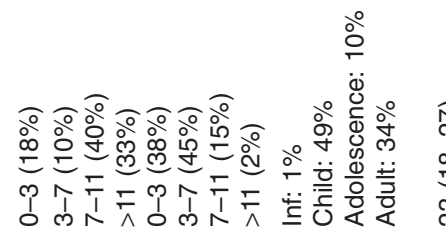

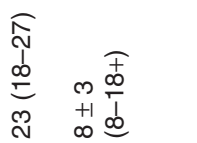

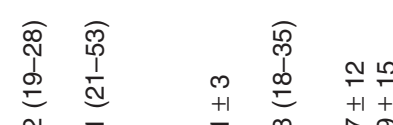

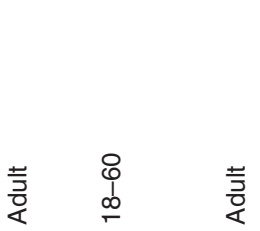

.

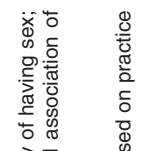

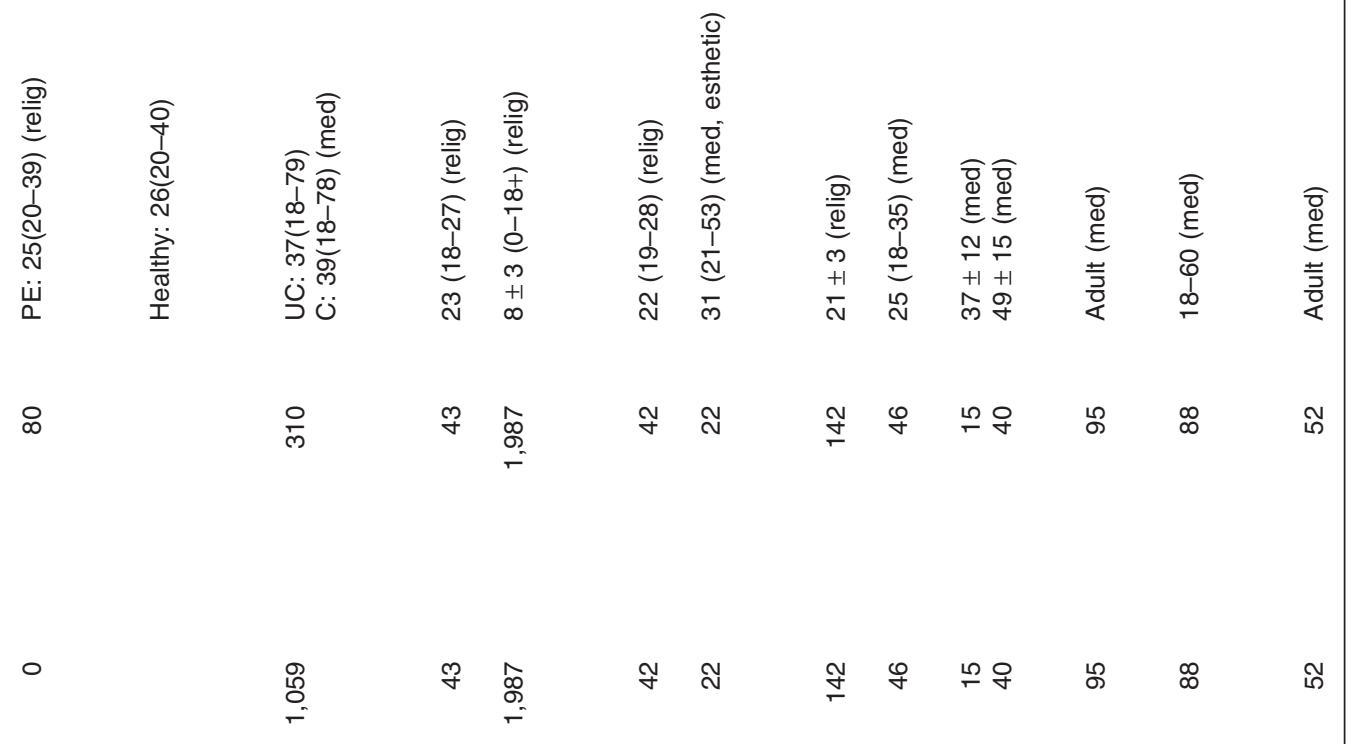

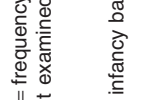

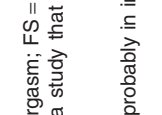

잉

喜

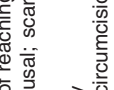

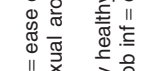

웡

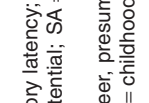

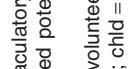

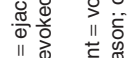

य)

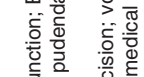

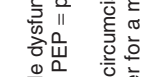

容产

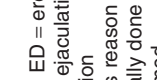

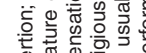

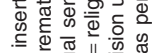

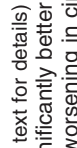

部

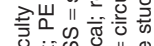

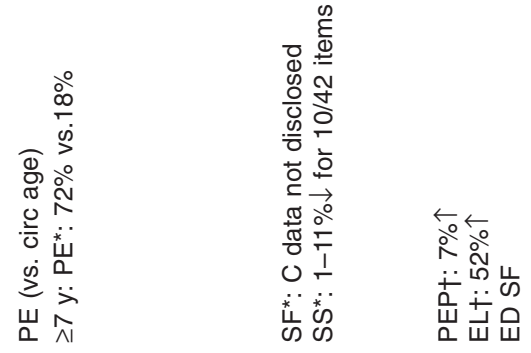

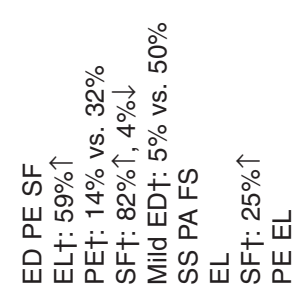

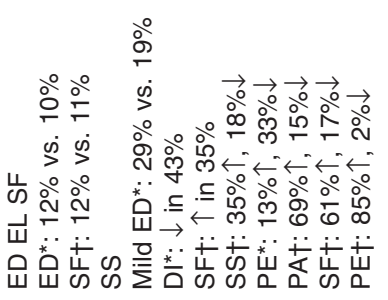

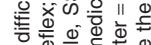

I1) 을

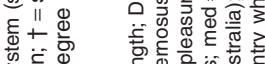

क्षे

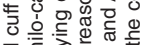

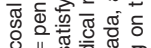

先

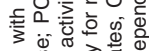

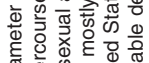

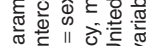

응 uㅐ

등

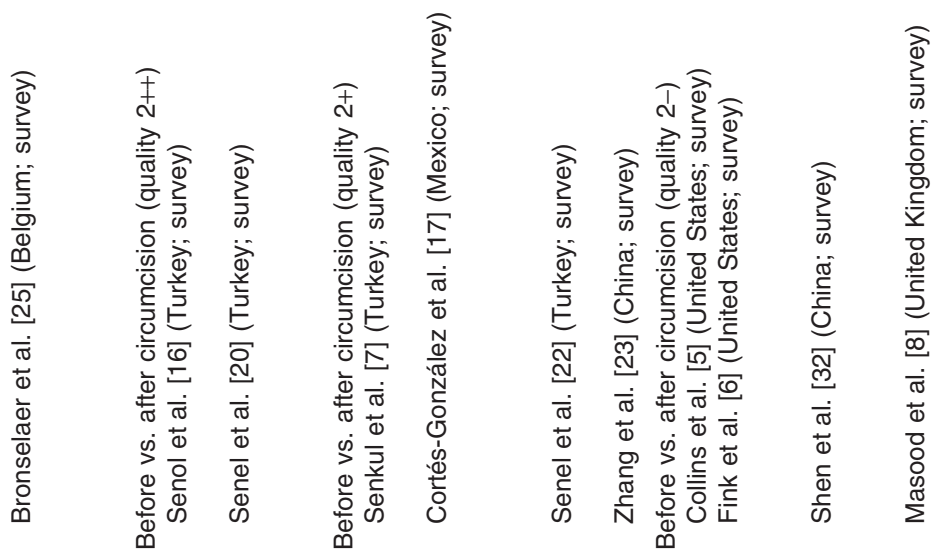

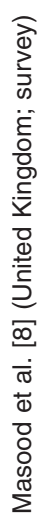

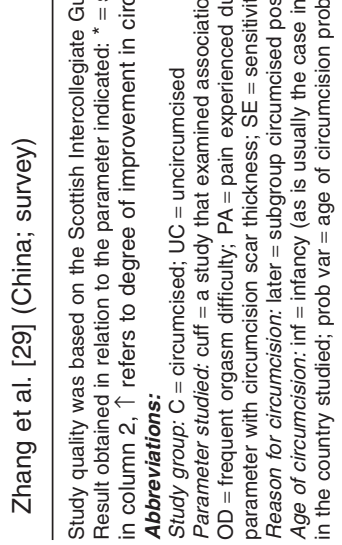


is too tight) [15]. Each group was questioned at baseline and at six monthly intervals up to 24 months postcircumcision. At each time point no statistically significant differences were found between the 1,391 men randomized to receive circumcision and the 1,393 men who remained uncircumcised. At each time point, the men who underwent circumcision were asked six additional questions to assess sexual function and pleasure compared with before they were circumcised. At 24 months, $99.9 \%$ of men were satisfied with their circumcisions. Penile sexual sensation had increased in $71.8 \%$ and was the same in $19.3 \%$. Ease of reaching orgasm was greater in $63.1 \%$ and the same in $22.4 \%$; frequency of sex was $38.8 \%$ and $34.7 \%$, respectively; feeling of being protected against sexual disease was $83.5 \%$ and $28.6 \%$, respectively; and, of those who had used a condom, ease of use was improved in $77.6 \%$ and was the same in $19.9 \%$. Odds ratios (OR) for "more" vs. "same," "less," or "don't know" at the 24 month follow-up visit were 2.83 (95\% CI, 2.40-3.33) for "penile sensitivity" (i.e., penile sexual sensation by our definition), 1.94 (1.67-2.26) for "ease of reaching orgasm," $0.68(0.59-0.79)$ for "frequency of sex," 5.03 (4.14-6.12) for "how protected do you feel against sexual disease," and 3.31 (2.71-4.03) for "ease of using a condom." Of the $92.4 \%$ of men whose sexual partners were aware of them having been circumcised, $64.9 \%$ of the partners were "very pleased," $3.3 \%$ were "somewhat pleased," $31.1 \%$ were "neutral or expressed no opinion," and none was "very displeased" $(\mathrm{OR}=1.94 ; 95 \%$ CI, 1.67-2.26).

The other RCT, in Uganda, involved 2,246 uncircumcised men compared with 2,210 randomized to receive circumcision. The authors found no difference in medium/high level of sexual desire, difficulty in achieving or maintaining an erection, difficulty with vaginal penetration, difficulty with ejaculation, or pain during or after intercourse [14]. At the 12-month time point, "sexual satisfaction rated as satisfied or very satisfied" was $99.7 \%$ and $99.0 \%$, in uncircumcised and circumcised men, respectively, and was $99.9 \%$ and $98.4 \%$ at 24 months.

$E D$

In American and European men, reported rates of $\mathrm{ED}$ are $37 \%, 34 \%$, and $40 \%$ for ages $18-30$, $31-50$, and $>51$ years, respectively [18].

The representative National Health and Social Life Survey of 1,410 U.S. men aged 18-59 years found that sexual dysfunctions were more common among uncircumcised men [40]. This was slight at younger ages, but became more frequent later in life (Table 3). Similarly, a large telephone survey of men aged 16-64 in Australia found that circumcised men reported fewer sexual difficulties for a month or more during the previous year [27]. Problems were reported most often among men over 50 years of age $(27 \%$ for uncircumcised and $15 \%$ for circumcised men) [27]. The difference became not statistically significant $(P=0.09)$ in a later survey of half of the subjects [39]. The latter study found that circumcised men were somewhat less likely to have worried during sex about whether their bodies looked unattractive (OR 0.77, 95\% CI 0.61-0.99; $P=0.04$ ). Masturbation was more common in the circumcised men (OR 1.2, 95\% CI 1.03-1.40; $P=0.02$ ), consistent with the U.S. study [40].

A survey of 84 men circumcised for benign diseases in London, England, found identical ED scores before and after circumcision [8]. Of these, $74 \%$ had no change in libido, $69 \%$ had less pain during intercourse $(P<0.05)$, and $44 \%$ of the men $(P=0.04)$ and $38 \%$ of the partners $(P=$ 0.02 ) thought that penile appearance was better after circumcision. Sensation improved in 38\% $(P=0.01)$, was unchanged in $44 \%$, and was worse in $18 \%$. Overall, $61 \%$ were pleased with their circumcision and $17 \%$ were not. If circumcision is for treatment of a medical problem, then the presence of permanent clinical or psychological impairment may explain why differences seen in the men circumcised as adults in this study are not typically seen in men circumcised neonatally [38].

A survey of 1,426 men who have sex with men found no overall differences between circumcised and uncircumcised men in participation in insertive or receptive anal intercourse, difficulty in using condoms, or sexual problems such as loss of libido [38]. Among the $91.9 \%$ who had engaged in any anal intercourse in the previous 6 months, $8.8 \%$ had been circumcised after infancy (because of phimosis or parental wishes). Of these men, $26.3 \%$ practiced anal intercourse that was exclusively "receptive only," whereas this value was $12.5 \%$ for men circumcised during infancy. Of the men circumcised later, the "insertive" role during anal sex was practiced exclusively by $14.5 \%$, whereas among those circumcised in infancy, $27.1 \%$ were "insertive only" $(P=0.001)$. Nominated preferences for anal intercourse stated by the men were "receptive only" for $32.0 \%$ of those circumcised after infancy vs. $19.1 \%$ for those circumcised in infancy. Only $22.7 \%$ of men 
circumcised after infancy preferred an insertive role compared with $32.1 \%$ of those circumcised in infancy $(P=0.02)$. Men circumcised later were more likely to experience erectile difficulties (52\% vs. $47 \%$; OR after adjustment for age and ethnicity $=1.66 ; 95 \%$ CI $1.01-2.70 ; P=0.04$; Table 3 ). Rather than anal intercourse practice and preferences being due to circumcision per se, the authors suggested that the differences reflected participant preferences that existed prior to circumcision that were likely influenced by foreskin pathologies such as phimosis.

A survey of 2,499 German men used the validated 35-item International Index of Erectile Dysfunction 6 (IIEF-6) plus additional relevant questions [26]. Of participants, 28\% reported moderate-to-severe ED and $12 \%$ reported minor ED. ED was independently influenced by history of smoking, hypertension, diabetes, chronic ischemic heart disease, peripheral vascular disease, cirrhosis, or history of pelvic surgery. In contrast, ED rates were not different for the $6.7 \%$ who were circumcised and the $93.3 \%$ who were uncircumcised [26].

A survey of 22 Mexican men circumcised mostly for medical reasons reported an improvement in perception of erectile function $(P=0.0007)$ and sexual events $(P=0.04)$ after circumcision [17].

The RCTs of generally young African men reported no significant difference in ED frequency at 24 months between the uncircumcised and circumcised $(0.1 \%$ vs. $0.3 \%$ [14] and $1.4 \%$ vs. $2.3 \%$ [15], respectively, for each RCT). A meta-analysis of six relevant studies $[14,15,19,27,32,40]$ concluded that circumcision did not affect ED [44] (Table 4).

\section{PE}

Because PE affects $15-30 \%$ of men, it is the most commonly reported male sexual dysfunction [46]. Based on the belief that the uncircumcised penis is more sensitive, circumcision has been used by some practitioners to treat PE $[23,29,47]$. Clinical research on $\mathrm{PE}$ has, however, been hampered by its complexity, interindividual variability, cultural differences, and subjectivity [46]. For example, a small survey in London found that immigrant men of Islamic or Asian background were more likely to report experiencing PE [48]. Sociosexual reasons such as the sexual excitement of the new cultural environment were said to be responsible, based on statements such as that life in London was, "like living in a pornographic shop."
Table 4 Summary of findings from a meta-analysis of suitable studies [44]

\begin{tabular}{|c|c|c|c|c|}
\hline Studies included & Total n & $\%$ affected & OR & $95 \% \mathrm{Cl}$ \\
\hline \multicolumn{5}{|l|}{ Erectile dysfunction } \\
\hline \multirow[t]{2}{*}[14,15,19,27,32,40]{} & C: 6,826 & 8.3 & 0.90 & $0.65-1.25$ \\
\hline & UC: 6,052 & 22.3 & & \\
\hline \multicolumn{5}{|c|}{ Ejaculatory latency time } \\
\hline \multirow{2}{*}[7,16,18]{} & C: 309 & NA & 1.33 & $0.69-1.25$ \\
\hline & UC: 332 & NA & & \\
\hline \multicolumn{5}{|c|}{ Premature ejaculation } \\
\hline \multirow[t]{2}{*}[15,19,27,38,40]{} & C: 7,695 & 24.4 & 1.12 & $0.89-1.42$ \\
\hline & UC: 6,326 & 31.0 & & \\
\hline \multicolumn{5}{|c|}{ Sexual desire low or lacking } \\
\hline \multirow[t]{2}{*}[14,19,27,40]{} & C: 6,826 & 21.8 & 0.99 & $0.90-1.08$ \\
\hline & UC: 6,052 & 29.9 & & \\
\hline \multirow{3}{*}{$\begin{array}{l}\text { Orgasm difficulties } \\
{[15,19,27,40]}\end{array}$} & & & & \\
\hline & C: 6,683 & 6.4 & 0.97 & $0.83-1.13$ \\
\hline & UC: 5,727 & 14.7 & & \\
\hline \multicolumn{5}{|l|}{ Dyspareunia } \\
\hline \multirow[t]{2}{*}[14,15,19,27,38,40]{} & C: 8,288 & 7.0 & 1.05 & $0.60-1.86$ \\
\hline & UC: 6,894 & 7.2 & & \\
\hline
\end{tabular}

$\mathrm{C}=$ circumcised $; \mathrm{UC}=$ uncircumcised

\section{Physiological Measurements}

Intravaginal ejaculatory latency time (IELT), the time from start of vaginal intromission to intravaginal ejaculation, can provide useful data on $\mathrm{PE}$. An IELT that is usually less than 1 minute is considered diagnosic of $\mathrm{PE}$ [49].

A study of 500 couples in which IELT was recorded by stopwatch and paper diary found IELT to be 6.7 minutes (range $0.7-44.1$ minutes) in circumcised men and 6.0 minutes (range 0.537.4) in uncircumcised men, a difference that was not statistically significant [9]. Similar times were observed in The Netherlands, UK, Spain, and the United States [9]. In contrast, in Turkey, the authors found time to ejaculation to be significantly less. In men aged 18-30 years, the study found that average time to ejaculation was $6.5 \mathrm{~min}$, compared with $4.3 \mathrm{~min}$ in men over 51 years of age $(P<0.0001)$. The data were not affected by condom use.

The researchers then repeated the study using a blinded timer device (to reduce bias) with different cohorts from these countries [18]. In circumcised men (excluding Turkey), mean IELT was $10.3 \pm 9.3 \mathrm{SD}$ minutes (range 0.6-52.7) and in uncircumcised men was $8.8 \pm 6.9 \mathrm{SD}$ minutes (range $0.3-38.6, P=0.13$ ). Median IELT times were 7.2 and 6.0, respectively (excluding Turkey: 4.4 minutes).

\section{Survey Studies}

The large RCT in Kenya found no difference in reported PE prevalence $(4.6 \%$ vs. $3.9 \%$, 
respectively) between uncircumcised and circumcised men at the 24-month time point [15].

A SIGN level 2++ study of men who have sex with men in Sydney found that circumcision later in life, but not in infancy, was associated with lower PE prevalence (15\% vs. $23 \%$, OR adjusted for age and ethnicity $=0.46,95 \%$ CI $0.24-0.89 ; P=0.02$ ) [38]. A Mexican study (level 2+) of 22 men circumcised for medical reasons $(86 \%)$ or aesthetics (14\%) found a reduction of PE from 32\% to 14\% after circumcision [17]. A small (level 2-) survey in Malaysia found that PE in $41 \%$ was predicted by circumcision status (adjusted OR $[\operatorname{adjOR}]=4.88$; 95\% CI 2.35-10.2), ED (adjOR $=4.91 ; 95 \%$ CI 2.27-10.6), sexual intercourse $\leq 5$ times a week (adjOR $=3.73 ; 95 \%$ CI 1.85-7.54), and Indian ethnicity (adjOR $=3.32 ; 95 \%$ CI 1.49-7.42) [21].

There were a number of SIGN 2+ studies from Turkey. One evaluated men before and 12 weeks after circumcision for religious $(n=39)$ or cosmetic $(n=3)$ reasons [7]. The authors found an increase in ejaculatory latency time that was considered an advantage by participants because they could prolong intercourse. A second study found no relationship between age of childhood circumcision and overall sexual function [10]. As Turkish men are usually circumcised during childhood, there was no uncircumcised control group. Of seven sexual functions examined (frequency of intercourse, communication, degree of satisfaction, avoidance, sensuality, ejaculatory function, and erectile function), the only difference was lower avoidance in those circumcised between age 0 and 2, compared with age 3-5 and age 6-12 years (Golombok-Rust Inventory of Sexual Function scores $=0.9 \pm 1.3,2.5 \pm 1.9$, and $1.7 \pm 1.7$, respectively; $P=0.016$ by ANOVA; prevalence of avoidance $=8.3 \%, 27.6 \%$, and $12.1 \%$, respectively, $P=0.12$ by $\chi^{2}$ ) [10] (Table 3 ). A later study found no differences in IIEF questionnaire scores (for erectile function, orgasm, sexual desire, intercourse satisfaction, and overall satisfaction), PE Diagnostic Tool, or Beck Depression Inventory questionnaire scores between men circumcised during the phallic period (3-6 years of age) and the nonphallic period [24]. A study of PE patients found that those circumcised after age 7 had a higher Golombok-Rust Inventory of Sexual Satisfaction PE subscale scores than those circumcised before the age of 7 years, leading the authors to recommend that circumcision be performed in the first 3 years of life [31].

A study in Beijing of men who underwent circumcision to treat PE, found no change in Brief
Male Sexual Function Inventory (BMSFI) scores 6 months after the procedure [23]. But circumcision of 52 Chinese men suffering from PE and redundant prepuce cured $55 \%$ by the 12 -month checkup [29]. PE was not associated with postcircumcision mucosal cuff length [13,36,37]. An Internet survey of Korean men found no association between circumcision status and PE [30]. The proportion of circumcised men in the study was not stated.

A meta-analysis of five studies $[15,19,27,38,40]$ found that circumcision does not affect $\mathrm{PE}$ prevalence [44] (Table 4).

\section{Orgasm Difficulties}

A Danish survey found that $10(11 \%)$ of 95 circumcised men reported "frequent orgasm difficulties" compared with 63 (4\%) of 1,694 uncircumcised men [19] (adjOR $=3.3 ; 95 \%$ CI 1.4-7.5). No differences were found in ED, PE, dyspareunia, or occasional orgasm difficulties.

A meta-analysis of four studies $[15,19,27,40]$, that included the Danish study, found that circumcision did not affect orgasm difficulties $(\mathrm{OR}=0.97)[44]($ Table 4).

\section{Difficulty with Penetration and Dyspareunia}

In the RCT in Kenya, at 6 months, the earliest time the men were examined after the procedure, difficulty with penetration was $1.4 \%$ in circumcised men and $0.6 \%$ in uncircumcised men, and pain on intercourse was $0.6 \%$ vs. $1.2 \%$ [15]. At 12 months and 24 months, penetration and pain were identical between the groups.

A meta-analysis of six studies [14,15,19,27, 38,40 ] that examined dyspareunia found that circumcision made no difference [44] $(\mathrm{OR}=1.05$; 95\% CI 0.60-1.86; Table 4).

\section{Penile Sensitivity}

Of two studies rated as SIGN level 2++, one older study involved clinical and neurological testing of the ventral and dorsal surfaces, as well as the glans, of the flaccid penis [43]. The authors found similar fine touch perception for circumcised and uncircumcised men. The other SIGN 2++ study included quantitative somatosensory testing (vibration, pressure, spatial perception, and hot and cold temperature testing) of different penile locations, including the foreskin, to evaluate the spectrum of small to large axon nerve fiber function [35]. The study found worse vibration sensation in uncircumcised men compared with men circumcised neonatally. This also applied in a subgroup of men with ED. After controlling for 
factors that can affect neurological testing, such as age, diabetes, and hypertension, no difference was statistically significant.

Two studies were of low quality (SIGN level 2-). A study from San Francisco, funded by the National Organization of Circumcision Information and Resource Centers, measured "fine-touch pressure sensitivity thresholds" on 17 locations on the uncircumcised penis and 11 locations on the circumcised penis, including nine sites common to both penis types [33]. The authors stated that "When compared with the most sensitive area of the circumcised penis [the ventral scar] several locations on the uncircumcised penis [i.e., 4 on the foreskin], which are missing from the circumcised penis, were more sensitive." Sensitivity of only one site ("the orifice rim") showed a statistically significant greater sensitivity (difference adjusted for age $=11 \% ; P=0.014$ ).

The other level 2- study used a clinical test devised by its author to determine the penilocavernosus reflex in middle-aged Slovenian men [34]. The study assessed the sacral (i.e., bulbocavernosus) reflex in men with suspected neurogenic causes of bladder, bowel, or sexual dysfunction by "brisk compression of the glans penis between the first three fingers." The study concluded that circumcised men exhibit lower neurophysiological excitability than uncircumcised men.

\section{Sexual Arousal Response and Penile Sensation during Arousal \\ Physiological Measurements}

We identified only one study that used physiological approaches to measure sexual arousal. This study assessed sexual arousal noninvasively using a thermal imaging camera [50]. Genital temperature measurements correlated with subjective arousal scores obtained on a Likert-style questionnaire [50]. Penile temperature was $1^{\circ} \mathrm{C}$ lower during a control stimulus (a travelogue) in the flaccid penis of uncircumcised men compared with the circumcised men [12]. An erotic stimulus (i.e., sexually arousing film) increased penile temperature to a similar plateau after 8 minutes for each penis type [12]. Subjective arousal scores from a questionnaire correlated with penile temperatures in both groups. More circumcised participants reported an increase in their level of sexual arousal, while more uncircumcised men reported being unaffected by the erotic stimulus. In each group, sensitivity to touch, measured on the penile shaft and glans, was lower during exposure to the erotic film, as compared with baseline or the control film. The authors suggested that a reduction in penile sensation during arousal might be necessary for the act of penile penetration.

\section{Survey Studies}

One of the RCTs surveyed sexual sensation [15]. At 24 months postcircumcision, $64 \%$ of participants reported that their penis was "much more sensitive," which, according to our terminology, meant they experienced greater sensation during sexual activity. Only 1.6\% said that their penis was "much less sensitive." These findings suggested that adult male circumcision has no adverse effect on penile sexual sensation. For some men penile sensation may have improved.

One study was rated as SIGN level 2+ [17] and another as 2- [8]. These were small and involved men circumcised for medical reasons. Neither study found any difference in sexual sensation comparing men before and after circumcision.

A nonvalidated "Self-Assessment of Genital Anatomy and Sexual Function, Male" questionnaire was administered to 70 circumcised and 11 uncircumcised U.S. men aged 22-57 years (mean $=33$ years) [51]. The authors found that penile sensitivity to sexual stimulation (i.e., "sexual sensation" by our terminology) was highest for the underside of the glans, followed by the underside of the shaft, upper side of the glans, left and right side of the glans, one or both sides of the penis, and upper side of the penile shaft. Of all parts of the penis, the foreskin was rated the least sensitive. The limited sample size and large number of comparisons obviated statistical comparisons of the circumcised and uncircumcised groups.

An online version of this 25-minute questionnaire was later used to survey men recruited at railway stations in Ghent, Belgium [25]. The authors reported findings for uncircumcised and circumcised men after rating six sites on the penis, although not the foreskin, for each of seven parameters, including sexual pleasure and orgasm intensity. Of the 42 measurements, 22 were statistically significant at $P<0.05$, uncorrected for multiple testing. Apart from "unusual sensations intensity" for the dorsal and lateral shaft that were, respectively, 37\% $(P=0.039)$ and $39 \%$ (not significantly) higher for uncircumcised men, 20 other significantly different values were merely $1 \%$ to $11 \%$ more favorable in uncircumcised men and one (orgasm intensity from stimulating the ventral shaft) was $8 \%$ higher in circumcised men. The authors nevertheless concluded that circumcised men experience lower penile sensitivity to sexual stimulation. 


\section{Sexual Satisfaction and Pleasure}

The large Ugandan RCT found no difference in sexual satisfaction and pleasure between circumcised and uncircumcised men over the 2 years of the trial [14]. At enrolment, sexual satisfaction rated as satisfied or very satisfied in uncircumcised men assigned to the circumcision arm of the trial was $98.5 \%$, and in men assigned to the uncircumcised arm was $98.1 \%(P=0.37)$. At the 24 -month time point of the trial, satisfaction rates were $98.0 \%$ and $99.4 \%(P=0.004)$ in each respective group. While satisfaction improved in the control uncircumcised men over the trial period $(P<0.001)$, no significant change was noted for the men in the circumcised arm $(P=0.81)$. In the large Kenyan RCT, seven potential indices of sexual pleasure were surveyed [15]. At 24 months postcircumcision, participants reported experiencing greater penile sexual sensation, ease in reaching orgasm, and frequency of sex (see "RCTs" section above for details).

The US National Health and Social Life Survey of 1,398 men reported that circumcised men engaged in a more elaborate set of sexual practices, suggesting they enjoyed a more varied sexual lifestyle, and that their female partners were more pleased with the esthetics of a circumcised penis [40]. Two subsequent U.S. surveys [5,6] found similar or greater sexual satisfaction among men circumcised as adults. There was no significant difference in sexual drive, erection, ejaculation, problem assessment, sensitivity, or satisfaction compared with what the men recalled sex being like prior to circumcision [5]. The larger of these two surveys (123 questionnaires sent but only $35 \%$ valid returns) found that $62 \%$ of men reported that they were satisfied with having been circumcised and liked their new appearance, 50\% reported benefits, but sexual activity was unchanged [6]. Penile sensitivity, although not tested directly, was thought by some of the participants to be slightly lower (score 11.2 before vs. 12.2 after circumcision; $P=0.04$ ). The authors suggested that this might have contributed to their claims of better sex. Some participants thought that their erectile function was slightly reduced (category scores: 12.3 vs. $11.1, P=0.05$ ), a finding opposite to the much larger US National Health and Social Life Survey [40]. The outcome might have been affected by the fact that $93 \%$ had been circumcised for medical problems (70\% for phimosis and 16\% for balanitis). Both the men and their partners preferred the appearance of the penis after circumcision. As in other studies $[39,40]$ oral sex became more frequent, but there was no change in anal sex [6]. After circumcision, participants reported that their partners were more likely to initiate sex.

A number of other survey studies considered in sections above also assessed sexual satisfaction and pleasure. The large German survey found that there was no significant correlation between sexual satisfaction and circumcision status $(r=-0.003$; $P=0.88$ ) [26]. Improvement in quality of sexual intercourse was reported by $82 \%$ of Mexican men, most of whom were circumcised for medical reasons [17]. Only $4.5 \%$ said quality had been diminished. A survey of Turkish men found no adverse effect of circumcision on sexual drive or ejaculation, whereas BMSFI scores for erectile function and satisfaction increased 8.2\% $(9.5 \pm 0.7$ before vs. $10.3 \pm 0.4$ after; $P=0.01)$ and $26 \%$ (3.1 \pm 0.2 vs. $3.9 \pm 0.6 ; P=0.01)$, respectively [22].

The pudendal-evoked potential is suggested as an objective tool to assess sexual satisfaction, as sensory stimuli on the glans and penis are transmitted centrally via the pudendal nerve. In young men, mean pudendal-evoked potential latency was $42.0 \pm 0.25$ milliseconds (mean \pm SD) before circumcision and $44.7 \pm 0.33$ milliseconds (mean $\pm \mathrm{SD})$ after circumcision $(P<0.001)$ [16] The authors suggested that circumcision might contribute to sexual satisfaction by prolonging intercourse time. The study also concluded that circumcision had no adverse effect on sexual function.

A SIGN level 2- Korean survey used the BMSFI to evaluate masturbatory pleasure in 373 men aged 30-57 years [11]. The study found that masturbatory pleasure was lower in $48 \%$ and greater in $8 \%$ of men after circumcision. While $63 \%$ said masturbation was more difficult after circumcision, $37 \%$ said it was easier. The study found no significant differences in sexual drive, erection, ejaculation, or ejaculatory latency time. Sexual pleasure was the same for $74 \%$, worse for $20 \%$, and better for $6 \%$.

A meta-analysis found that low sexual desire was not associated with circumcision status $(21.7 \%$ vs. $29.9 \%$, OR 0.99 ; $95 \%$ CI $0.90-1.08$, for circumcised vs. uncircumcised men) [44] (Table 4).

\section{Discussion}

This systematic review finds no evidence overall for any significant difference in components of sexual function, sensitivity, sexual sensation, or sexual pleasure in men who are circumcised and men who are not. Of particular interest were 
studies of men circumcised in adulthood because these men served as their own control. We found a wide range of study quality, with the better-quality studies, such as RCTs and a meta-analysis (level $1++)$, failing to find any adverse effect of circumcision on the parameters examined. In contrast, some lower-quality studies reported various adverse effects from circumcision.

A particularly strong study was one conducted in Montreal that examined sensation during arousal [50]. It addressed the topic using three different approaches: physiological measurement of sexual arousal noninvasively, determination of sensitivity of the penis to touch, and use of a questionnaire that correlated men's subjective arousal scores with measurements from thermal imaging. Other strong evidence included measurement of IELT in two successive populations in five countries, finding no difference between circumcised and uncircumcised men $[9,18]$. The above findings confirmed results from good studies both previously and subsequently that each involved a single method. Although two of the high-quality studies were large RCTs $[14,15]$, these too were based on a single modality, namely survey data.

Histological studies have attempted to correlate structures such as Meissner's corpuscles, genital corpuscles, and free nerve endings, with findings from the studies of function, sometimes with conflicting conclusions. A review of relevant histological information will be the subject of a separate article. While Meissner's corpuscles detect touch, sexual sensation involves genital corpuscles. The latter are present in the body of the penis, but absent from the foreskin [52].

It is well known that there are individuals in society who are opposed to male circumcision for various reasons, and this can include some researchers and clinicians. In assessing the current circumcision-related topic, we regarded it as important to the integrity of our systematic review to include all eligible studies and assess the quality and strength of the evidence to be found in each. In so doing, we rated several studies as level 2-. We will now discuss some of the shortcomings of particular studies in order that the reader might appreciate why they received a level 2 - rating.

A study in San Francisco that found higher sensitivity of only "the orifice rim" of four locations on the foreskin when compared with the ventral scar of the circumcised penis [33], made this claim based on a $P$ value of 0.014 that was age adjusted, but was not corrected for multiple statistical tests performed. If it had been corrected, then the significance would have been lost [53]. Those who criticized that study used its data to compare the nine locations comr@ to the circumcised and uncircumcised penis and found no significant difference, even without correction for multiple testing [53]. Aspects of study design, including modes of subject recruitment, were also criticized [53].

The level 2- study that used an idiosyncratic clinical test devised by the study author to determine the penilo-cavernosus reflex in middle-aged Slovenian men [34] claimed that circumcised men had lower penile sensitivity. However, no difference was observed by neurophysiological testing. The article noted that the finding was not consistent with data from the United States, where most men are circumcised and the penilo-cavernosus reflex can be elicited by clinical testing in $98 \%$ of men [54]. Although the author described how the 30 circumcised and 15 uncircumcised men with retracted foreskins were identified, he did not comment on why data for only 29 of the 202 uncircumcised men with their foreskin in place were presented, and no demographic information was provided.

A Belgian survey that reported lower sexual sensation in circumcised men [25] was rated as SIGN 2- for the following reasons: Although the paper reported the percentage of uncircumcised men who rated sexual pleasure and orgasm intensity as "mild" to "very strong," the percentages for circumcised men were not stated. The statistical analyses did not correct for multiple testing whereas a Bonferroni correction was performed in the study that developed the questionnaire used [51]. It is doubtful that the small statistically significant differences of $1 \%$ to $11 \%$ for all but one (of $37 \%$ ) identified in uncorrected statistical tests are biologically significant [55]. It seems unlikely that a man could accurately know whether orgasm intensity would vary depending on the specific site of stimulation, for example, if it would be greater for stimulating, say, the lateral shaft of his penis by itself. Close inspection of the data reveal various anomalies. The $\mathrm{n}$ values for each of the 42 measurements made in each group were not stated. Nor was variance such as \pm SD reported, whereas it was in the study that developed the questionnaire used [51]. Curiously, while some differences of $1 \%$ or $2 \%$ (favoring the uncircumcised) were highly significant, a difference of $39 \%$ showing higher "unusual sensations intensity" of the lateral penile shaft of uncircumcised men was not significant, 
whereas a $37 \%$ greater difference for the dorsal shaft was $(P=0.039)$. Although the questionnaire used by Bronselaer et al. had been developed earlier by its second author (J.S.) and included questions on the foreskin, curiously, unlike that author's 2009 U.S. study [51], the Belgian study did not report foreskin data, nor whether data for the foreskin differed from values for other sites on the penis in uncircumcised men. Doing so would have been valuable. The proportion of circumcised men in the survey (23\%) was much higher than the circumcision rate in Europe generally, consistent with selection bias in the self-selected convenience sample surveyed. In Europe, circumcision for nonreligious reasons is usually for treatment of a medical problem, such as balanitis, balanitis xerotica obliterans, or phimosis that can have long-lasting effects on sexual function [38]. Circumcision for a medical reason has been suggested as an explanation for the findings $[55,56]$.

A Korean study that reported a decrease in masturbatory pleasure after adult circumcision [11] has been criticized for its lack of recruitment information, the fact that only 138 "sexually experienced" men of the 255 circumcised men recruited were questioned about their sex lives, including masturbation, before and after circumcision, the presentation of data on masturbation but not sexual intercourse, no statement on type of circumcision, contradictory statements about scarring, and confusion of male sexual response with sexuality [57].

In the Danish study that found more frequent orgasm difficulties in circumcised men, a number of flaws have been identified [58]. The analyses were not corrected for multiple testing, which if performed, would have negated the finding. Only half of those invited to participate did so. Infant circumcision is uncommon in Denmark. Of the circumcised men, $85 \%$ were circumcised later, most likely for a medical reason as they had listed that they had no religion or were Lutheran, a known noncircumcising denomination in Europe. Circumcision for medical reasons may be independently associated with sexual dysfunction. According to an Australian study of men who have sex with men, males circumcised after infancy for medical reasons were more likely to exhibit psychologically based behavioral aversion to penetrative sex [38]. In Denmark, medical circumcisions, mostly for phimosis, tend to involve a dorsal slit, meaning the foreskin is not removed [58]. One might expect that individuals having a strong opinion would be more likely to partici- pate, representing a potential bias. These flaws resulted in a SIGN level 2- classification. The American Academy of Pediatrics Task Force on Circumcision made similar criticisms of the Danish study [59].

\section{Conclusions}

This systematic assessment of the literature found that higher-quality studies (SIGN level 1++ through 2+) show that male circumcision has no adverse effect on parameters relevant to sexual function, sensation, sensitivity, satisfaction, or pleasure, especially when the circumcision is performed in infancy. The parameters that define sexual function include frequency of $\mathrm{ED}, \mathrm{PE}$, orgasm difficulties, difficulty with penetration, and dyspareunia. Future research should include more high-quality designs, such as large RCTs in developed countries, physiological testing of men for multiple parameters, that have to date only been applied to individual study cohorts, more welldesigned survey studies that limit recruitment bias, and improvements in existing questionnaires. Based on available data to date, it is likely that such high-quality studies will further confirm that circumcision does not reduce any sexual function or sensation parameter, or diminish sexual pleasure.

Corresponding Author: Brian J. Morris, DSc, PhD, School of Medical Sciences, Building F13, University of Sydney, Sydney, NSW 2006, Australia., Tel: +61-29351-3688; Fax: +61-2-9351-3688; E-mail: brian .morris@sydney.edu.au

Conflict of Interest: The authors report no conflicts of interest.

\section{Statement of Authorship}

\section{Category 1}

(a) Conception and Design

Brian J. Morris; John N. Krieger

(b) Acquisition of Data

Brian J. Morris

(c) Analysis and Interpretation of Data

Brian J. Morris; John N. Krieger

\section{Category 2}

(a) Drafting the Article

Brian J. Morris; John N. Krieger

(b) Revising It for Intellectual Content Brian J. Morris; John N. Krieger 


\section{Category 3}

(a) Final Approval of the Completed Article Brian J. Morris; John N. Krieger

\section{References}

1 Cox G, Morris BJ. Why circumcision: From pre-history to the twenty-first century. In: Bolnick DA, Koyle MA, Yosha A, eds. Surgical guide to circumcision. London: Springer; 2012:24359.

2 American Academy of Pediatrics. Male circumcision. (Technical Report) Task Force on Circumcision. Pediatrics 2012;130: e756-85.

3 Morris BJ, Wodak AD, Mindel A, Schrieber L, Duggan KA, Dilly A, Willcourt RJ, Cooper DA, Lumbers ER, Russell CT, Leeder SR. Infant male circumcision: An evidence-based policy statement. Open J Prev Med 2012;2:79-82.

4 Morris BJ, Wiswell TE. Circumcision and lifetime risk of urinary tract infections: A systematic review and meta-analysis. J Urol 2013;189:2118-24.

5 Collins S, Upshaw J, Rutchik S, Ohannessian C, Ortenberg J, Albertsen P. Effects of circumcision on male sexual function: Debunking a myth? J Urol 2002;167:2111-2.

6 Fink KS, Carson CC, deVellis RF. Adult circumcision outcomes study: Effect on erectile function, penile sensitivity, sexual activity and satisfaction. J Urol 2002;167:2113-6.

7 Senkul T, Iseri C, Sen B, Karademir K, Saracoglu F, Erden D. Circumcision in adults: Effect on sexual function. Urology 2004;63:155-8.

8 Masood S, Patel HRH, Himpson RC, Palmer JH, Mufti GR, Sheriff MKM. Penile sensitivity and sexual satisfaction after circumcision: Are we informing men correctly? Urol Int 2005; 75:62-6.

9 Waldinger MD, Quinn P, Dilleen M, Mundayat R, Schweitzer $\mathrm{DH}$, Boolell M. A multinational population survey of intravaginal ejaculation latency time. J Sex Med 2005;2:492-7.

10 Aydur E, Gungor S, Ceyhan ST, Taiimaz L, Baser I. Effects of childhood circumcision age on adult male sexual functions. Int J Impot Res 2007;19:424-31.

11 Kim D, Pang MG. The effect of male circumcision on sexuality. BJU Int 2007;99:1169-70.

12 Payne K, Thaler L, Kukkonen T, Carrier S, Binik Y. Sensation and sexual arousal in circumcised and uncircumcised men. J Sex Med 2007;4:667-74.

13 Hosseini SR, Khazaeli MH, Atharikia D. Role of postcircumcision mucosal cuff length in lifelong premature ejaculation: A pilot study. J Sex Med 2008;5:206-9.

14 Kigozi G, Watya S, Polis CB, Buwembo D, Kiggundu V, Wawer MJ, Serwadda D, Nalugoda F, Kiwanuka N, Bacon MC, Ssempijja V, Makumbi F, Gray RH. The effect of male circumcision on sexual satisfaction and function, results from a randomized trial of male circumcision for human immunodeficiency virus prevention, Rakai, Uganda. BJU Int 2008;101: $65-70$.

15 Krieger JN, Mehta SD, Bailey RC, Agot K, Ndinya-Achola JO, Parker C, Moses S. Adult male circumcision: Effects on sexual function and sexual satisfaction in Kisumu, Kenya. J Sex Med 2008;5:2610-22.

16 Senol MG, Sen B, Karademir K, Sen H, Saraçoğlu M. The effect of male circumcision on pudendal evoked potentials and sexual satisfaction. Acta Neurol Belg 2008;108:90-3.

17 Cortés-González JR, Arratia-Maqueo JA, MartínezMontelongo R, Gómez-Guerra LS. [Does circumcision affect male's perception of sexual satisfaction?]. [Article in Spanish]. Arch Esp Urol 2009;62:733-6.

18 Waldinger MD, McIntosh J, Schweitzer DH. A five-nation survey to assess the distribution of the intravaginal ejaculatory latency time among the general male population. J Sex Med 2009;6:2888-95.

19 Frisch M, Lindholm M, Grønbeck M. Male circumcision and sexual function in men and women: A survey-basedcross-sectional study in Denmark. Int J Epidemiol 2011;40: $1367-81$.

20 Senel FM, Demirelli M, Pekcan H. Mass circumcision with a novel plastic clamp technique. Urology 2011;78:174-9.

21 Tang WS, Khoo EM. Prevalence and correlates of premature ejaculation in a primary care setting: A preliminary crosssectional study. J Sex Med 2011;8:2071-8.

22 Senel FM, Demirelli M, Misirlioglu F, Sezgin T. Adult male circumcision performed with plastic clamp technique in Turkey: Results and long-term effects on sexual function. Urol J 2012;9:700-5.

23 Zhang GX, Yu LP, Bai WJ, Wang XF. Selective resection of dorsal nerves of penis for premature ejaculation. Int J Androl 2012;35:873-9.

24 Armagan A, Silay MS, Karatag T, Akman T, Tepeler A, Ersoz C, Akcay M. Circumcision during the phallic period: Does it affect the psychosexual functions in adulthood? Andrologia 2013. [Epub ahead of print].

25 Bronselaer GA, Schober JM, Meyer-Bahlburg HF, T'Sjoen G, Vlietinck R, Hoebeke PB. Male circumcision decreases penile sensitivity as measured in a large cohort. BJU Int 2013;111: $820-7$.

26 Hoschke B, Fenske S, Brookman-May S, Spivak I, Gilfrich C, Fritsche HM, Wolff I, May M. [Male circumcision is not associated with an increased prevalence of erectile dysfunction: Results of the Cottbus 10,000-men survey]. [Article in German]. Urologe A 2013;52:562-9.

27 Richters J, Smith AM, de Visser RO, Grulich AE, Rissel CE. Circumcision in Australia: Prevalence and effects on sexual health. Int J STD AIDS 2006;17:547-54.

28 Boyle GJ, Bensley GA. Adverse sexual and psychological effects of male infant circumcision. Psychol Rep 2001;88(Pt 2):1105-6.

29 Zhang SJ, Zhao YM, Zheng SG, Xiao HW, He YS. [Correlation between premature ejaculation and redundant prepuce]. [Article in Chinese]. Zhonghua Nan Ke Xue 2006;12:225-7.

30 Son H, Song SH, Kim SW, Paick JS. Self-reported premature ejaculation prevalence and characteristics in Korean young males: Community-based data from an Internet survey. J Androl 2010;31:540-6.

31 Cüceloğlu EA, Hoşrik ME, Ak M, Bozkurt A. The effects of age at circumcision on premature ejaculation. Turk Psikiyatri Derg 2012;23:99-107.

32 Shen Z, Chen S, Zhu C, Wan Q, Chen Z. [Erectile function evaluation after adult circumcision]. [Article in Chinese]. Zhonghua Nan Ke Xue 2004;10:18-9.

33 Sorrells ML, Snyder JL, Reiss MD, Eden C, Milos MF, Wilcox N, Van Howe RS. Fine-touch pressure thresholds in the adult penis. BJU Int 2007;99:864-9.

34 Podnar S. Clinical elicitation of the penilo-cavernosus reflex in circumcised men. BJU Int 2012;109:582-5.

35 Bleustein CB, Fogarty JD, Eckholdt H, Arezzo JC, Melman A. Effect of neonatal circumcision on penile neurological sensation. Urology 2005;65:773-7.

36 Bodakçi MN, Bozkurt Y, Söylemez H, Hatipoglu NK, Penbegül N, Atar M, Sancaktutar AA. Relationship between premature ejaculation and postcircumcisional mucosal cuff length. Scand J Urol Nephrol 2013. [Epub ahead of print].

37 Tarhan H, Can E, Akdeniz F, Akarken I, Cakmak O, Zorlu F. Relationship between circumcision scar thickness, postcircumcision mucosal cuff length measures and premature ejaculation. Scand J Urol Nephrol 2013;47:328-32.

38 Mao LM, Templeton DJ, Crawford J, Imrie J, Prestage GP, Grulich AE, Donovan B, Kaldor JM, Kippax SC. Does 
circumcision make a difference to the sexual experience of gay men? Findings from the Health in Men (HIM) Cohort. J Sex Med 2008;5:2557-61.

39 Ferris JA, Richters J, Pitts MK, Shelley JM, Simpson JM, Ryall R, Smith AMA. Circumcision in Australia: Further evidence on its effects on sexual health and wellbeing. Aust N Z J Public Health 2010;34:160-4.

40 Laumann EO, Maal CM, Zuckerman EW. Circumcision in the United States. Prevalence, prophyactic effects, and sexual practice. J Am Med Assoc 1997;277:1052-7.

41 Bollinger D, Van Howe RS. Alexithymia and circumcision trauma: A preliminary investigation. Int J Mens Health 2011; 10:184-95.

42 Hammond T. A preliminary poll of men circumcised in infancy or childhood. BJU Int 1999;83(suppl 1):85-92.

43 Masters WH, Johnson VE. Human sexual response. Boston, MA: Little Brown; 1966.

44 Tian Y, Wang J, Wazir R, Yue X, Wang K. Effects of circumcision on male sexual functions: A systematic review and meta-analysis. Asian J Androl 2013. [Epub ahead of print]. doi: 1038/aja2013.47.

45 Harbour R, Miller J. A new system for grading recommendations in evidence based guidelines. BMJ 2001;323:334-6.

46 Sadeghi-Nejad H, Watson R. Premature ejaculation: Current medical treatment and new directions (CME). J Sex Med 2008;5:1037-50.

47 Gallo L. Patients affected by premature ejaculation due to glans hypersensitivity refuse circumcision as a potential definite treatment for their problem. Andrologia 2013. [Epub ahead of print].

48 Richardson D, Goldmeier D. Premature ejaculation-Does country of origin tell us anything about etiology? J Sex Med 2005;2:508-12.

49 McMahon CG, Althof SE, Waldinger MD, Porst H, Dean J, Sharlip ID, Adaikan PG, Becher E, Broderick GA, Buvat J, Dabees K, Giraldi A, Giuliano F, Hellstrom WJ, Incrocci L,
Laan E, Meuleman E, Perelman MA, Rosen RC, Rowland DL, Segraves R. An evidence-based definition of lifelong premature ejaculation: Report of the International Society for Sexual Medicine (ISSM) ad hoc committee for the definition of premature ejaculation. J Sex Med 2008;5:1590-606.

50 Kukkonen TM, Binik YM, Amsel R, Carrier S. Thermography as a physiological measure of sexual arousal in both men and women. J Sex Med 2007;4:93-105.

51 Schober JM, Meyer-Bahlburg HF, Dolezal C. Self-ratings of genital anatomy, sexual sensitivity and function in men using the "Self-Assessment of Genital Anatomy and Sexual Function, Male" questionnaire. BJU Int 2009;103:1096-103.

52 Rhodin JAG. Histology. London: Oxford University Press; 1974.

53 Waskett JH, Morris BJ. Fine-touch pressure thresholds in the adult penis. (Critique of Sorrells ML et al. BJU Int 2007;99:864-869). BJU Int 2007;99:1551-2.

54 Blaivas JG, Zayed AA, Labib KB. The bulbocavernosus reflex in urology: A prospective study of 299 patients. J Urol 1981;126:197-9.

55 Morris BJ, Krieger JN, Kigozi G. Male circumcision decreases penile sensitivity as measured in a large cohort. [Critique of Bronselaer et al. BJU Int 2013; 111: 820-827]. BJU Int 2013; 111:E269-70.

56 Hegarty PK. Male circumcision decreases penile sensitivity as measured in a large cohort. (Editorial). BJU Int 2013;111: 695-6.

57 Willcourt R. Critique of: "The effect of male circumcision on sexuality" by Kim KD, Pang M. BJU Int 2006;99:619-622. BJU Int 2007;99:1169-70.

58 Morris BJ, Waskett JH, Gray RH. Does sexual function survey in Denmark offer any support for male circumcision having an adverse effect? Int J Epidemiol 2012;41:310-2.

59 Task Force on Circumcision. Cultural bias and circumcision: The AAP Task Force on Circumcision Responds. Pediatrics 2013;131:801-4. 